\title{
Removal Phosphorus in Pollution Water by Composite Aluminum Electrode
}

\author{
Lixia Wang, Zhihui Liu , Juan Wang, Shu Zhang \\ Institute of Engineering and Technology, \\ Yunnan University, \\ Kunming, 650091, China
}

\begin{abstract}
Based on the method of homogeneous composite aluminum electrode with pulse electric field to removal phosphorus in moderately pollution water, which is expressed the effect of operation time and electric field intensity on it. The results shows that when the $\mathrm{pH}=6-7$, reaction time $60 \mathrm{mins}$, electric field strength $60 \mathrm{~V} / \mathrm{cm}$, the phosphorus removal rate is $88.91 \%$. The method of phosphorus removal by composite aluminum electrode pulse electric field has a space to further raise and improvement.
\end{abstract}

Keywords-phosphorus pollution; phosphorus; pulse electric field; aluminum electrode

\section{INTRODUCTION}

The major effect of phosphorus is the eutrophication. Usually when the concentration of phosphorus exceed $0.02 \mathrm{mg} / \mathrm{L}$, it will produce eutrophication ${ }^{[1]}$; when the phosphorus concentration more than $20 \mathrm{mg} / \mathrm{L}$, it will accelerate eutrophication ${ }^{[2]}$. There are 37 major typical lakes in our country, where, $55.8 \%$ with moderate nutritional types and moderate to severe nutritional types, eutrophication accounts for $14.7 \%$, highly eutrophication accounts for $8.8 \%{ }^{[3-4]}$. China's regulations: The allowable maximum emissions concentration of phosphorus in sewage is $0.5 \mathrm{mg} / \mathrm{L}$ (GB8978-1996) ${ }^{[5]}$.

At present, the main methods for phosphorus removal are chemical and biological. The efficiency of the chemical method is highly, but the problem is that there are a large amount of wastes and secondary pollution; biological phosphorus removal method can avoid a lot of chemical sludge which produced by chemical method, and can reduce the swelling phenomenon of activated sludge and energy conservation, but there are poor running stability and strong dependence in biological method ${ }^{[6-9]}$. Pulse electric field method is further improvement on the physical methods which is based on the DC electric field. In this paper, based on the method of homogeneous composite aluminum electrode with pulse electric field to removal phosphorus in moderately pollution water, in order to improve and complete the removal of phosphorus at the physical method, hoping to deal with today's phosphorus pollution problems in a new perspective. With the study of phosphorus removal in moderate concentration of phosphorus pollution water can carry the purposes of high efficiency and safety.

\section{TEST METHODS}

In the study, removal phosphorus, homemade pulse electric device used, while the homogeneous composite aluminum electrode used. The sample of phosphorus pollution water are taken directly from Yunnan Yang Zong Hai spring, concentration is $16.26 \mathrm{mg} / \mathrm{L}, \mathrm{pH}=6 \sim$ 7. Each series of experiments add the same amount of water, in the affect of pulse electric field, discussing the influence of phosphorus removal by the action time and the electric field strength parameters. The samples are tested by ammonium molybdate spectrophotometer method.

\section{ANALYSIS AND DISCUSSION}

\section{A. Results and Analysis of the Electric Field Strenght on Phosphorus Removal}

In pulse electric field, composite aluminum electrode is used, time is set 10 minutes, plate spacing are fixed $15 \mathrm{~cm}, 10 \mathrm{~cm}, 5 \mathrm{~cm}$, the peak voltage is 220V,240V,260V,280V,300V,320V. Corresponding electric field strength is expressed intensity 1, 2, 3. By adjusting the voltage, discussing the electric field strength, impacted on the phosphorus removal. The results are shown in Table I.

TABLE I. ELECTRIC FIELD STRENGTH PHOSPHORUS REMOVAL PHOSPHORUS CONCENTRATION CHANGES IN THE ELECTRIC FIELD STRENGTH 1

\begin{tabular}{llllll}
\hline $\begin{array}{l}\text { Electric field } \\
\text { intensity (V/cm) }\end{array}$ & 14.67 & 16 & 17.33 & 18.67 & 20 \\
\hline $\begin{array}{l}\text { Phosphorus } \\
\text { concentration (mg/l) }\end{array}$ & 10.42 & 9.47 & 7.49 & 7.34 & 7.23 \\
$\begin{array}{l}\text { Original phosphorus } \\
\text { concentration (mg/l) }\end{array}$ & 16.24 & 16.24 & 16.24 & 16.24 & 16.24 \\
\hline
\end{tabular}

PHOSPHORUS CONCENTRATION CHANGES IN THE ELECTRIC FIELD STRENGTH 2

\begin{tabular}{llllll}
\hline $\begin{array}{l}\text { Electric field } \\
\text { intensity }(\mathrm{V} / \mathrm{cm})\end{array}$ & 22 & 24 & 26 & 28 & 30 \\
\hline $\begin{array}{l}\text { Phosphorus } \\
\text { concentration (mg/l) }\end{array}$ & 10.34 & 9.30 & 7.39 & 7.28 & 6.93 \\
$\begin{array}{l}\text { Original phosphorus } \\
\text { concentration (mg/l) }\end{array}$ & 16.24 & 16.24 & 16.24 & 16.24 & 16.24 \\
\hline
\end{tabular}


PHOSPHORUS CONCENTRATION CHANGES IN THE ELECTRIC FIELD STRENGTH 3

\begin{tabular}{|c|c|c|c|c|c|}
\hline $\begin{array}{l}\text { Electric field intensity } \\
(\mathrm{V} / \mathrm{cm})\end{array}$ & 44 & 48 & 52 & 56 & 60 \\
\hline $\begin{array}{l}\text { Phosphorus } \\
\text { concentration (mg/l) }\end{array}$ & 10.34 & 8.45 & 7.45 & 7.24 & 6.77 \\
\hline $\begin{array}{l}\text { Original phosphorus } \\
\text { concentration (mg/l) }\end{array}$ & 16.24 & 16.24 & 16.24 & 16.24 & 16.24 \\
\hline
\end{tabular}

As can be seen from Table I, with the increase of electric field intensity, phosphorus concentration is decreased. In order to exhibit changes of phosphorus concentration more clearly, a histogram has been made, show in Figure 1.

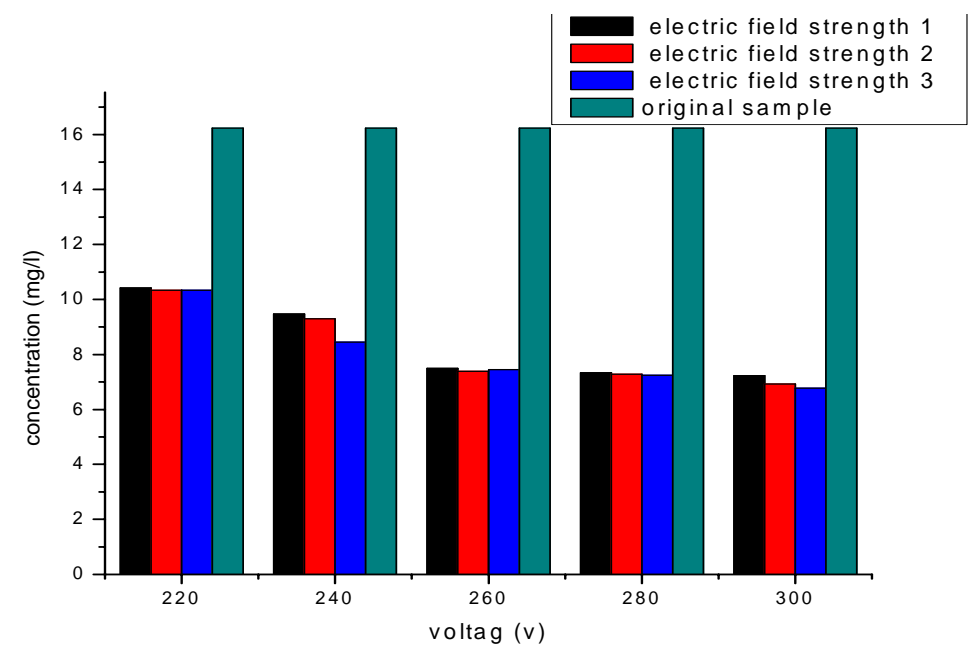

Figure 1. Phosphorus concentration changes in different electric field intensity

As can be seen from Figure 1, in the same voltage, the effect of electric field strength on phosphorus concentration is not obvious. The value of the electric field intensity 1, 2, 3 are closed; in the same plate spacing, the impact of electric field strength on the phosphorus concentration shows a decreasing trend, but at a voltage of $260 \mathrm{~V}, 280 \mathrm{~V}, 300 \mathrm{~V}$, the curve change gently and the phosphorus concentration is closed. When operation time is $10 \mathrm{~min}$, the electric field strength is $60 \mathrm{v} / \mathrm{cm}$, the phosphorus concentration is $6.77 \mathrm{mg} / \mathrm{l}$, and phosphorus removal rate is $58.3 \%$.

\section{B. Results and Analysis of Time on Phosphorus Removal}

In pulse electric field, composite aluminum electrode is used in the method, and the field strength is $60 \mathrm{v} / \mathrm{cm}$, the time is adjusted to discuss the effect of phosphorus removal. The results are shown in Table II.

TABLE II. PHOSPHORUS CONCENTRATION CHANGES IN OPERATION TIME

\begin{tabular}{lllllll}
\hline time (min) & 10 & 20 & 30 & 40 & 50 & 60 \\
\hline $\begin{array}{l}\text { Phosphorus } \\
\text { concentration (mg/l) }\end{array}$ & 6.77 & 4.72 & 3.69 & 2.99 & 2.61 & 1.80 \\
$\begin{array}{l}\text { Original phosphorus } \\
\text { concentration (mg/l) }\end{array}$ & 16.24 & 16.24 & 16.24 & 16.24 & 16.24 & 16.24 \\
\hline
\end{tabular}

As can be seen from Table II, in the 60 minutes makes phosphorus removalrate reached $88.91 . \%$, which shown that the operation time on the removal of phosphorus in pollution water are better, (Figure 2): 


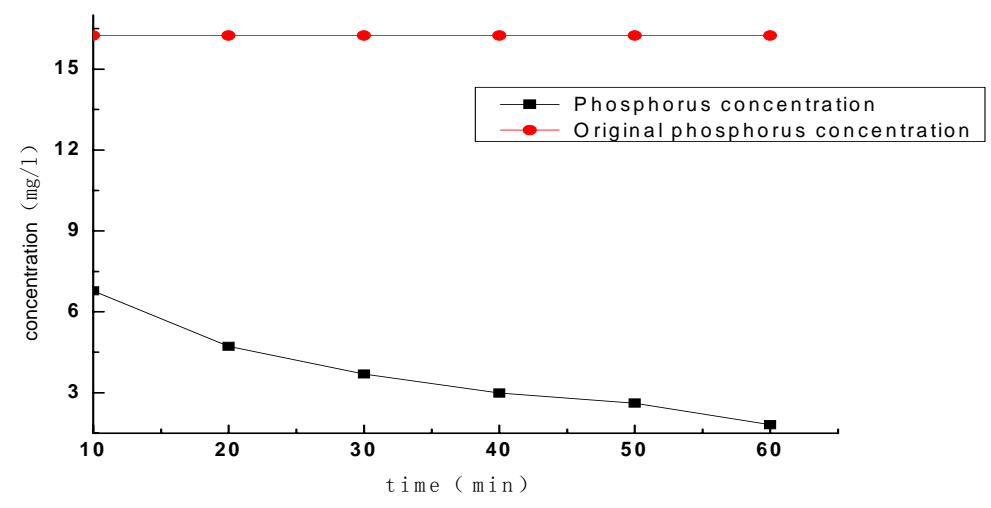

Figure 2. phosphorus concentration changes in operation time

As can be seen from Figure 2, in the same electric field intensity, with the time increasing, the phosphorus concentrations are gradually decreased. So effect on phosphorus concentration changes is obvious. When the operation time is 60 minutes, the electric field strength is $60 \mathrm{v} / \mathrm{cm}$, the phosphorus content is $1.80 \mathrm{mg} / \mathrm{l}$, the phosphorus removal rate is $88.91 \%$.

\section{CONCLUSION}

Based on the method of homogeneous composite aluminum electrode with pulse electric field to removal phosphorus in moderately pollution water, which is expressed the effect of operation time and electric field intensity on it, making the phosphorus concentration decrease gradually.

1. Homogeneous composite aluminum electrode pulse electric field method is easy to operate. The total phosphorus concentration is relatively reduction, and it reaches the cleaning requirements.

2. In the same voltage value, with the electric field intensity increasing, the phosphorus concentration is declined, but the change is slowly.

3. The highest phosphorus removal rate by composite aluminum electrode is $88.91 \%$. The value of phosphorus concentration doesn't reach the standards. Action time, voltage and pulse width can be improved in following studies in order to make the phosphorus removal rate increased to reach the emission standards.

\section{ACKNOWLEDGEMENTS}

The research work was supported by the sixth postgraduate student innovation project of Yunnan University under Grant No.YNUY201312 and Yunnan University fund under Grant No. 2013CG030 and No. 2012CG013.

\section{REFERENCES}

[1] LiuNing, Xiaona, Li Bingjie, etc. phosphorus wastewater treatment methods hazards and Research [J], survival and development, 2013,2; 90-92

[2] Gao Wei Sheng, chemical precipitation treatment High Phosphorus in Wastewater [J], Industrial Water \& Wastewater,2012,4,43:24 26

[3] Wang Wei. Study on preparation of Modified Zeolite and the Phosphates Removal properties[D].Changchun: Jilin University,2010.

[4] Zhiling Xu, Juan Wang, Yanan Liu, Shu Zhang, "Research on the effect of electric field to phosphorus removal in industrial phosphorus-rich wastewater," Conference on Evironmental Pollution and Public Health (CEPPH2011),Wuhan China, vol. 2, pp. 1072-1075, September 16 17 2011.

[5] Bureau of Technical Supervision.GB8978-1996, Integrated Wastewater Discharge Standard[S],1998.1.1.

[6] Li Shuyuan, HUANG Xia, LIANG Peng, iron anode electrolytic flocculation Condition of phosphorus removal [J], Water \& Wastewater, 2007, 33, Suppl: 94-99

[7] Zhong, Wang Rio, Liu Yuan, et al, waste incineration fly ash handling high concentrations of phosphorus wastewater dynamics [J]. Civil and Environmental Engineering, 2009, 31 (5):117-121.

[8] Yang Hui, Xue Jianjun, Wang Ling, et al, ultrasound / Phosphorus from Wastewater microelectrolysis co [J]. Water Technology, 2011, 37 (2): 85-89.

[9] ShangXiao,Wang,Xinze,Mei-ling. High Phosphorus in wastewater phosphorus removal electrolysis technology[J]. Water Purification Technology, 2009, 28 (1): 43-46. 